\title{
ИЗ ИСТОРИИ РАСКОПОК МАВЗОЛЕЯ АВГУСТА
}

\author{
(C) 2020 г. А.Ю. Маркелов
}

В статье рассматривается история раскопок крупнейшей римской гробницы, а именно мавзолея императора Цезаря Августа. Основное внимание уделяется результатам недавних археологических работ и тому, как они повлияли на представление о памятнике. Гробница первого римского императора в пост-античную эпоху претерпела различные трансформации и неоднократные грабежи, в результате которых сильно пострадала. Памятнику находили практическое применение вплоть до 1930-х гг. За многовековую историю мавзолей использовали как каменоломню, крепость, которую не раз разрушали, виноградник, сад, амфитеатр для корриды, театр и концертный зал. Первые археологические работы на территории памятника проводились уже в XVI в. Именно с них начинается история исследования монумента и результаты, полученные тогда, до сих пор имеют большое значение для науки. На протяжении длительного времени после эпохи Ренессанса объект изучался только периодически, в связи с какими-либо строительными работами, проводившимися на его территории. Работы на памятнике активизируются с начала XX в. Масштабные раскопки состоялись в 1920-30-е гг. Их проведение диктовалось не научными целями: Бенито Муссолини стремился использовать римское наследие в своей пропаганде. Тем не менее, в результате проведенных работ мавзолей был не только освобожден от пост-античных наслоений, но полученные тогда результаты заложили современное представление о памятнике. Интерес к мавзолею возобновляется только через семьдесят лет. Непосредственным толчком было решение реконструировать мавзолей и площадь вокруг него. В результате раскопок, проведенных департаментом культурного наследия столицы Рима, были получены археологические данные, изменяющие взгляд на внешний облик монумента и позволяющие поставить точку в дискуссии по данному вопросу.

Ключевые слова: история археологических раскопок, погребальная архитектура, погребения, реконструкция, Август, Цезарь Август, мавзолей Августа, тумулус, толос.

\section{FROM THE HISTORY OF EXCAVATIONS OF AUGUSTAN MAUSOLEUM}

\section{A.Yu. Markelov}

The paper addresses the history of excavations of the largest Roman tomb, the Mausoleum of the Emperor Caesar Augustus. The author focuses on the results of recent archaeological activities and how they have transformed the perception of the monument. The tomb of the first Roman Emperor in the post-classical era underwent various transformations and was repeatedly plundered. As a result, the tomb has preserved in a severely damaged condition. The monument had been used for utilitarian purposes until the 1930s. The mausoleum was used as a quarry, a fortress which has been repeatedly destroyed, a vineyard, a garden, an amphitheater for bullfighting, a theater, and a concert hall. The first archaeological excavation in the territory of the monument was carried out in the $16^{\text {th }}$ century. It is them which marked the beginning of the monument's study history. The material obtained during these field works is still of great importance for scholars who engage in the study of the monument. For a long time after the Renaissance era the Mausoleum was studied only periodically due to construction works carried out in its territory. The archaeological study of the monument has intensified since the beginning of the $20^{\text {th }}$ century. Ambitious works were carried out in the 1920s and 1930s. Their implementation was not dictated by scholarly interest: Benito Mussolini sought to use the heritage of Ancient Rome for his propaganda. Nevertheless, as a result of the completed excavations, the mausoleum was not only freed from the post-antique layers, but the obtained results laid the foundation for the modern idea of the monument. New interest in the monument arose only after seventy years. The immediate reason to that was the government's plan for the reconstruction of the mausoleum and the surrounding area. Excavations were carried out by the Department of Cultural Heritage of the Capital of Rome. The obtained archaeological data have greatly changed the modern perception of the monument and make it possible to put an end to the discussion of the issue.

Keywords: history of archaeological excavations, funerary architecture, burials, reconstruction, Augustus, Caesar, Mausoleum of Augustus, tumulus, tholos. 
Гробницы - одни из самых изученных материальных свидетельств римской культуры (Borg, 2019, XV; Diebner, 2013, p. 67). Тем не менее даже в истории известнейших памятников римской погребальной архитектуры имеется еще много нерешенных проблем. Один из примеров - это крупнейшая римская гробница, а именно мавзолей первого римского императора Цезаря Августа, расположенный в северной части Марсового поля в Риме вблизи Тибра (Boschung, 1980, p. 38; Johnson, 1996, p. 217, 221-222; Davies, 2000, p. 14, 49). Датировка строительства монумента дискутируется в антиковедении, однако бесспорно, что это случилось еще при жизни императора и в самом начале его правления (Albers, 2014, p. 16).

Единственное описание сооружения сохранил младший современник императора Августа греческий географ Страбон (Strabo. V.3.8). Он называет конструкцию мавзолеем ( M $\alpha \sigma \sigma \dot{\lambda} \varepsilon 10 v)$. Согласно его сообщению, монумент представлял собой стоящий у реки большой могильный холм на высоком фундаменте, сделанном из белого мрамора, покрытый до вершины вечнозелеными деревьями (غ่ліे

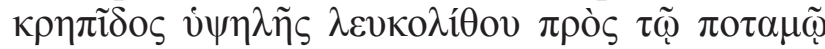

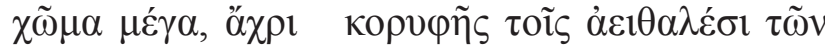

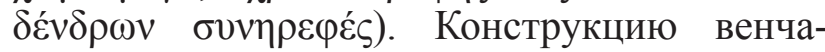
ла бронзовая статуя Цезаря Августа ('ं ' $^{\prime}$

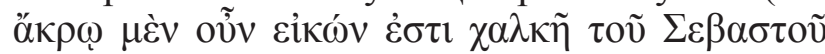

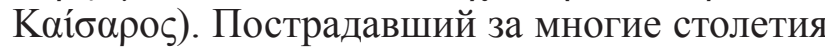
от многочисленных трансформаций и перестроек памятник сохранился до наших дней.

C данным монументом связан целый комплекс дискутируемых научных проблем, имеющих в том числе археологический характер, в частности, внешний вид и конструкция гробницы, образцы погребальных сооружений, повлиявшие на конструкцию сооружения и т. д. Их решение имеет значение не только для понимания развития римских гробниц, но вообще для понимания истории погребальной архитектуры Евразии периода древности. Разрешение указанных вопросов невозможно без привлечения данных, полученных в результате археологических раскопок.

Цель нашей работы - проанализировать историю раскопок мавзолея Августа. Бытование памятника в эпоху Средних веков, Нового времени и история начала раскопок достаточно хорошо изучены (Lanciani, 1897, p. 464-466; Lanciani, 1903, p. 13-19; Nash, 1961, p. 38; Riccomini, 1996; Hase Salto von, 1997, p. 297-308; Ortolani, 2004, p. 197-198). Поэтому мы сосредоточимся на недавних работах и том, как их результаты повлияли на изменение представлений о памятнике. Это совершенно неизвестный для отечественной науки аспект развития работ, связанных с упомянутым археологическим памятником.

Прежде чем обратиться к результатам недавних археологических раскопок, проводившихся на территории мавзолея Августа, необходимо рассказать о судьбе объекта в постантичную эпоху.

Несмотря на все перипетии, гробница Августа никогда не пребывала в безвестности. Наиболее вероятно, что мавзолей сильно пострадал в период варварских нашествий на Рим и сильно затронувших его военных действий V-VI вв. н. э. Первое упоминание мавзолея в период Средних веков относится к $\mathrm{X}$ в. В дипломе папы римского Агапита II, датируемом 952 г., сообщается о церкви Сан-Анджело де Агосто, расположенной на вершине холма. В Средние века монумент часто именовали «Augustum». Например, в средневековом анонимном путеводителе по Риму XII в. он именуется именно так (Mirabilia Romae 30). Использовались и другие названия: «Mons Augusti», «Austa» или просто «L'austa» (Hase Salto von, 1997, p. 298; Fugate Brangers, 2007, p. 83-88; Betti, 2011, p. 22).

В XII в. монумент превратили в крепость, которая была уничтожена в 1167 г., затем могущественная семья Колонна ее восстановила. Во владении этой семьи он оставался до XIV века. Когда надобность в крепости отпала, здание было передано во владение мирянам, превратившим мавзолей в виноградник. Как и многие другие памятники Античности, мавзолей сильно страдал от использования его в качестве каменоломни. Найденные на территории мавзолея античные предметы использовали под бытовые нужды. Так, урну, в которой был когда-то прах Агриппины Старшей - матери императора Калигулы, отвезли на рынок и стали использовать при измерении объема пшеницы. В начале XVI в. мавзолеем стала владеть влиятельная римская семья Орсини. В это время памятник представлял собой большой холм. В 1546 г. мавзолей был куплен Ф. Содерини, который превратил его в сад, где экспонировались различные антики. В XVII в. сад, некогда пользовавшийся большой популярностью, начал приходить в упадок, a вокруг памятника выстроили различные постройки. В последующие два века мавзолей не раз менял владельцев, реже его функцио- 
нал. Внутри мавзолея был построен амфитеатр, где проводилась коррида и давались фейерверковые представления. Эти действа пользовались успехом, в результате чего был возведен каменный амфитеатр (получивший название Anfiteatro Correa) над третьим кольцом стены сооружения. В XIX в. мавзолей был переоборудован под театр, покрытый стеклянным куполом. По разным причинам театр был закрыт, а постройку стали использовать как склад для материалов, необходимых для возведения монумента в честь короля Виктора Иммануила (Hase Salto von, 1997, p. 228-305; Lanciani, 1897, p. 464-466; Lanciani, 1903, p. 13-19; Fugate Brangers, 2007, p. 90-103; Agnoli et al, 2014, p. 215).

В конце XIX - начале XX вв. снова возрос интерес к использованию мавзолея. В результате в 1907 г. он открыл свои двери как концерт-холл города Рима под именем «Augusteo». В таком качестве он просуществовал до 13.08.1936. С этого времени он стал выполнять роль исключительно археологического объекта и достопримечательности (Hase Salto von, 1997, p. 306; Fugate Brangers, 2007, p. 103, 114). Выше были даны лишь основные события, значительным образом повлиявшие на неполную сохранность археологического памятника. Фактически сохранилась только нижняя часть архитектурного объема мавзолея Августа. Это соответствует трети первоначальной высоты. Из-за такого состояния памятника конструкция мавзолея до сих пор является предметом дискуссий в среде специалистов (Agnoli et al, 2014, p. 216).

Отдельные археологические раскопки предпринимались уже в начале XVI в. Непосредственной причиной их проведения в это время были планы папы Льва X по переустройству данной части города. Привлеченные к работам архитекторы Б. Перуцци и А. да Сангалло Младший задокументировали все находки, особенно имевшие место в 1519 г. Оставленные ими рисунки и заметки являются начальной точкой исследования памятника. Рисунки Б. Перуцци относятся к юго-западной части мавзолея. Без них невозможно было бы восстановить архитектурный облик отдельных элементов гробницы. Во время данных раскопок был найден один из двух обелисков, размещавшихся перед входом в мавзолей. Кроме того, при проведении строительных работ в непосредственной близости к мавзолею и во время его реконструкций волей не волей происходили своего рода раскопки, делались различные находки (Hesberg, Panciera, 1994, p. 9-10; Agnoli et al, 2014, p. 216; Fugate Brangers, 2007, p. 92-98).

Необходимо отметить работы, проводившиеся во второй половине XVIII в., так как во время этих раскопок было сделано несколько важных открытий. В 1781 г. был найден второй из обелисков. В 1794 г. проводились археологические изыскания внутри мавзолея, цель которых состояла не только в поиске скульптур, но и установлении плана гробницы. К сожалению, об этих изысканиях практически ничего не известно. В течение следующих более чем ста лет никаких работ научного характера на территории памятника не проводилось (Lanciani, 1897, p. 466; Hase Salto von, 1997, p. 303; Fugate Brangers, 2007, p. 98-102; Agnoli et al, 2014, p. 217).

В 1907-1908 гг. были проведены раскопки ограниченного масштаба, в ходе которых удалось найти античный вход в гробницу. Исследования археологического объекта активизировались в 1920-1930-е гг. в эпоху диктатора Б. Муссолини, который широко использовал образ Древнего Рима в своей пропаганде, в особенности архитектурные памятники (Hase Salto von, 1997, p. 306; Nash, 1961, p. 38; Fugate Brangers, 2007, p. 107; Fugate Brangers, 2013, p. 125; Betti, 2011, p. 34; Agnoli et al, 2014, p. 217). 01.04.1924 Мусслолини объявил о планах по приданию нового облика Риму. Планировалось модернизировать город, вместе с тем сделать доступными для обозрения памятники античного Рима. Предполагалось расчистить пространство вокруг мавзолея Августа, театра Марцелла, Капитолийского холма, реорганизовать территорию нескольких античных форумов, провести раскопки на площади Торре-Арджентина, работы на холме Оппий, на территории Большого Цирка, императорских форумов. В указанные годы в Риме были развернуты огромные по размаху археологические раскопки. Работы были настолько грандиозными, что Муниципальная археологическая комиссия Рима специально ассигновала крупные суммы на фотографическую кампанию, призванную документировать все действия. В результате было сделано 7 тыс. фотоснимков (Parker, 1989, p. 139-140; McFeaters, 2007, p. 55; Tittoni, 2011, p. 11).

Раскопки с 1926 по 1930 гг. проводились под научным руководством двух известных итальянских археологов Дж. Джильоли и А. Колини. По результатам они опублико- 
вали работы, в которых охарактеризовали состояние объекта, использованные при его строительстве материалы, описали находки, среди которых были скульптуры, надписи, погребальные урны (Colini, Giglioli, 1926, p. 191-237; Giglioli, Colini, 1930; Fugate Brangers, 2007, p. 109-111; Betti, 2011, p. 35). Раскопки возобновились в 1934 г. в связи с подготовкой к двухтысячелетней годовщине со дня рождения первого римского императора. Предполагалось полностью освободить мавзолей от построек, окружавших его, и сделать гробницу центром новой проектируемой площади. В открытии работ участвовал лично Б. Муссолини. Раскопки и сопутствующие работы длились до 1937 г., в результате чего объект был полностью очищен от позднейших пристроек. К сожалению, эти работы были плохо задокументированы. Результаты работ не оправдали возлагаемых надежд на попытку реконструкции памятника. Начальник экспедиции А. Муноз надеялся, что получится восстановить план здания, однако в ходе работ смогли установить только план большой наружной стены и задокументировать структуру и толщину полукруглых ниш между двумя наружными стенами (Nash, 1961, p. 38; Fugate Brangers, 2007, p. 113-116; Betti, 2011, p. 35-36).

После работ 1930-х гг. раскопки были приостановлены, а планы по реставрации мавзолея свернуты из-за войны. В среде специалистов в целом к раскопкам тех лет отношение достаточно негативное из-за целей и методики проведения работ (Parker, 1989, p. 139-140; McFeaters, 2007, p. 57-58; Betti, 2011, p. 39). Тем не менее нельзя не признать, что благодаря тем раскопкам представления о конструкции мавзолея и его истории сильно продвинулись. По их результатам итальянский антиковед $Г$. Гатти предложил реконструкцию, которая была принята значительным числом специалистов. Согласно его представлению, мавзолей стоит отнести к башенному типу. Г. Гатти предположил, что надстройка была круглым храмом. До раскопок 1934-1937 гг. реконструкции мавзолея почти для всех его частей носили чрезвычайно спорный характер (Gatti, 1938, p. 1-17; Hesberg, Panciera, 1994, p. 2; Reeder, 1992, p. 270; Fugate Brangers, 2007, p. 115; Vögtle, 2008, p. 63).

Результаты работ были обобщены и проанализированы только через несколько десятилетий, когда в 1994 г. вышла книга «Мавзолей Августа. Строение и его надписи», принад- лежащая перу немецкого археолога X. фон Хезберга и итальянского эпиграфиста С. Панчиеры (Hesberg, Panciera, 1994).

Крупных раскопок не предпринималось до второй половины 2000-х гг. В 1995-1996 гг. Э. Бухнер из Германского археологического института провел ограниченные по масштабам работы перед мавзолеем. Их результаты были опубликованы практически сразу после завершения работ. Последние были направлены на решение дискутировавшегося вопроса о месте расположения двух обелисков, обрамлявших вход в мавзолей. Первый раскоп заложили на расстоянии 22 м от входа в гробницу. Сначала обнаружили остатки мола и канала, по которому многотонные обелиски транспортировали от р. Тибр к месту установки. Ширина мола составляла 4 м. Он шел тангенциально по отношению к усыпальнице. Затем был обнаружен фундамент мавзолея, более 10 м. После закладки еще нескольких шурфов было найдено основание восточного обелиска, затем другого, расположенного западнее мавзолея. Оказалось, что они имеют разный план: левый - форму прямоугольника с размерами 5,25×3,90 м., а правый - квадрата со сторонами 4,15 м. Усиленный фундамент левого обелиска, видимо, диктовался тем, что он находился на краю мола. Были обнаружены ступени, ведущие в мавзолей. Важной находкой стало обнаружение оснований двух столбов, располагавшихся почти у самой гробницы на расстоянии 60 см от стены. Судя по форме основания, оба имели квадратную форму со сторонами 1,49 м. На них был выгравирован перечень деяний императора Августа, составленный им самим (Buchner, 1996, p. 162-168).

Широкомасштабные раскопки, организованные департаментом культурного наследия столицы Рима, стартовали в сентябре 2007 г. и шли до 2011 г. Их проведение связано с планом реконструкции мавзолея и архитектурного преобразования пространства вокруг гробницы согласно плану архитектора Ф. Челлини, проект которого победил на конкурсе в 2006 г. Рабочая группа состояла из С. Ла Манна, Н. Агноли, Е. Карнабуччи, Е. Марии Лорети. Раскопки проводились М. Коллети и Л. Браччаленти (La Manna et al, 2008; Agnoli et al, 2014, p. 225; Urbanistica.comune.roma.it; Coletti, Maria Loreti, 2016, p. 304).

В зону работ вошел весь периметр пьяцца Аугусто Императоре. Исследованию были подвергнуты Мавзолей и прилегающий к нему район, а также значительные по разме- 
рам территории перед ним. Были проведены точные геоархеологические исследования с целью определения условий окружающей среды в районе до строительства мавзолея. Был предпринят стратиграфический анализ всех сохранившихся частей объекта, датируемых широким хронологическим интервалом между августовской эпохой и 1930-ми гг. Полученные данные были полезны для определения некоторых аспектов техники строительства, планиметрической и архитектурной планировки гробницы. Здание организовано вокруг цилиндрической структуры, которая опоясывается концентрическими стенами, традиционно обозначающимися номерами от 0 до 5. Могильная камера имела четырехугольную планировку. Камера, ограниченная стеной № 1, достигалась через галереи стен № 2 и № 3. Большой интерес представляют исследования, проведенные в восточном сектор мавзолея, включающем стены № 1 и № 3. Исследования показали более сложную организацию внутреннего пространства, чем предполагалось ранее. Интерпретация стены № 2 вызывала сложности. Из-за своей огромной толщины - 5,7 м - она обычно интерпретировалась как нижняя часть высокого барабана, увенчанного дорическим антаблементом. В результате работ стало ясно, что, за исключением короткого участка, сохранившиеся остатки можно отнести не к стене, а к коридору, включенному между двумя уже известными галереями. Согласно выводам итальянских археологов, кольцевой барабан, ранее помещавшийся над стеной № 2, должен был располагаться над № 3. Отдельные исследования были проведены в двух сериях комнат, ограниченных стенами № 3, № 4 и № 5, где сохранилась большая часть внутренней отделки эпохи Августа. В ходе работ был сделан важный вывод относительно внешнего облика мавзолея. Периметровая стена мавзолея, перепроектированная во время работ 1930-х гг., должна была иметь более высокий уровень, чем нынешняя. Эти данные важны, так как традиционно здание представлялось ученым состоящим из концентрических кольцевых объемов, уменьшающихся по мере возвышения здания. Археологические свидетельства говорят в пользу другой конструкции мавзолея. Он представлял собой насыпь, окруженную снаружи мощной цилиндрической стеной (Agnoli et al, 2014, p. 219-221).

За пределами гробницы были проведены археологические исследования к югу от памятника. Тщательный анализ показал, что обустройство южной области было завершено в несколько этапов. Это следует интерпретировать как различные стадии реализации единого и четко определенного проекта, а не как последовательность различных дополнений. Установлено, что первоначально не было дорожного покрытия и уровень земли вокруг памятника должен был соответствовать уровню первой ступени лестницы, находящейся на высоте 10,25 м над уровнем моря. Что касается обелисков, то было обращено внимание на то, что они расположены на разном удалении от здания: западный обелиск расположен на расстоянии $36 \mathrm{M}$, а восточный - на расстоянии 39 м. В 2012 г. проводились работы по изучению дренажной системы мавзолея. Реставрационные работы продолжаются (Agnoli et al, 2014, p. 221-222; Carnabucci, Agnoli, Maria Loreti, 2012; Sovraintendenzaroma.it; Coletti, Maria Loreti, 2016, p. 307-309).

Итак, трансформации, которым подверглась гробница императора Августа на протяжении веков, сильно осложняют ее изучение. Исследование памятника началось в XVI веке. Уже тогда были собраны важные для реконструкции здания данные. Однако до начала XX в. предпринимались эпизодические раскопки. По-настоящему изучение мавзолея началось в 1920- гг. Именно тогда было заложено представление о памятнике, сохранявшееся до недавнего времени. Раскопки, активизировавшиеся в 2000-е гг, сильно изменяют сложившиеся взгляды на реконструкцию монумента.

\section{ИСТОЧНИКИ И ЛИТЕРАТУРА}

Agnoli N., Carnabuci E., Caruso G., Maria Loreti E. Il Mausoleo di Augusto. Recenti scavi e nuove ipotesi ricostruttive // Apoteosi. Da uomini a dei. Il Mausoleo di Adriano, Catalogo della Mostra / Eds. Abbondanza L., Coarelli F., Lo Sardo E. Roma: Munus, Palombi, 2014. P. 214-229.

Albers $J$. Die letzte Ruhestätte des Augustus: Neue Forschungsergebnisse zum Augustusmausoleum // Antike Welt. 2014. №4. P. 16-24.

Betti F. Il Mausoleo di Augusto. Metamorfosi di un monument // Mausoleo di Augusto. Demolizioni e scavi. Fotografie 1928/1941 / Ed. F. Betti. Milano: Electa, 2011. P. 20-41. 
Borg B. Roman Tombs and the Art of Commemoration: Contextual Approaches to Funerary Customs in the Second Century CE. Cambridge: Cambridge University Press, 2019. 368 p.

Boschung D. Tumumuls Iuliorum - Mausoleum Augusti // Hefte des Archäologischen Seminars der Universität Bern. 1980. №6. S. 38-41.

Buchner E. Ein Kanal für Obelisken vom Mausoleum des Augustus in Rom // Antike Welt. Vol. 27. №3. S. $161-168$.

Carnabucci E., Agnoli N., Maria Loreti E. Mausoleo di Augusto. 2012. URL: http://www.fastionline.org/ excavation/micro_view.php?fst_cd=AIAC_2307\&curcol=sea_cd-AIAC_4480. Дата обращения 30.05.2020

Coletti C.M., Naria Loreti E. Piazza Augusto Imperatore, excavations 2007-2011: the late antiquetransformations // MAAR. 2016. № 61. P. 304-325.

Collini M. A., Ciglioli G.Q. Relazione della prima campagna di scavo nel Mausoleo di Augusto // BCom.1926. №54. P. 191-237.

Davies P.J.E. Death and the Emperor: Roman Funerary Monuments from Augustus to Marcus Aurelius. Cambridge, New York: Cambridge University Press, 2000. 256 p.

Diebner S. Tombs and Funerary Monuments // A Companion to the Archaeology of the Roman Republic / Ed. J. DeRose Evans. Malden: Wiley-Blackwell, 2013. P. 67-80.

Fugate Brangers S. L. Political Propaganda and Archaeology: The Mausoleum of Augustus in the Fascist Era // International Journal of Humanities and Social Science 2013. № 3. P. 126-135.

Fugate Brangers $S$. L. The mausoleum of Augustus: expanding meaning from its inception to present day. $\mathrm{PhD}$ diss. Louissville, 2007. 220 p.

Gatti G. Nuove osservazioni sul Mausoleo di Augusto // L'Urbe 1938. № 3. P. 1-17.

Giglioli, G.Q. and A. M. Colini. II Mausoleo d'Augusto. Milan and Rome: Bestetti e Tumminelli, 1930. $51 \mathrm{p}$.

Hase Salto M. A. von «L'augusteo» Das Augustusmausoleum im Wandel der Geschichte // Antike Welt. 1997. № 28. S. 297-308.

Hesberg H., Panciera S. Das Mausoleum des Augustus. Der Bau und seine Inschriften. München: Bayerische Akademie der Wissenschaften, 1994. 199 p.

Johnson M.J. The Mausoleum of Augustus: Etruscan and Other Influences on its Design // Etruscan Italy. Etruscan Influences on the Civilizations of Italy from Antiquity to the Modern Era / Ed. John F. Hall. Provo, 1996. P. 217-239.

La Manna S., G. Caruso, Agnoli N., Carnabucci E., Loreti E., Documento preliminare alla progettazione. 2008 URL: http://sovraintendenzaroma.it/sites/default/files/storage/original/application/368fc32a188973a805 57f3f49e3409f3.pdf. Дата обращения 28.05.2020.

Lanciani R. Storia degli scavi di Roma e notize intorno le collezioni Romane di antichità. Vol. II. Roma: Ermanno Loescher\&Co, 1903. 277 p.

Lanciani R. The Ruins and Excavations of Ancient Rome. London: Mac Millan, 1897. 700 p.

McFeaters, A. P. The Past Is How We Present It: Nationalism and Archaeology in Italy from Unification to WWII // Nebraska Anthropologist. 2007. №33. P. 49-69.

Mirabilia Romae e codicibus vaticanis emendate / G. Parthey (ed.). Berolini: in aedibus Frederici Nicolai, $1869.85 \mathrm{p}$.

Nash E. Pictorial Dictionary of Ancient Rome. Vol .I. London: A Zimmer Ltd., 1961. 532 p.

Ortolani G. Ipotesi sulla struttura architettonica originaria del Mausoleo di Augusto // BCom. 2004. Vol. 105, P. 197-222.

Parker J. Politics, Urbanism, and Archaeology in "Roma capitale": A Troubled Past and a Controversial Future // The American Journal of Archaeology. 1989. № 93. P. 137-141.

Reeder J.C. Typology and Ideology in the Mausoleum of Augustus: Tumulus and Tholos // Classical Antiquity. 1992. № 11. P. 265-307.

Riccomini A.M. La Ruina di si bela cosa. Vicende e transformationi del Mausoleo di Augusto. Milano: Electa, 1996. 202 p.

Sovraintendenzaroma.it. URL: http://www.sovraintendenzaroma.it/i_luoghi/roma_antica/monumenti/ mausoleo_di_augusto. Дата обращения 01.06.2020

Tittoni M.E. Introduzione // Il Mausoleo di Augusto. Metamorfosi di un monument Mausoleo di Augusto. Demolizioni e scavi. Fotografie 1928/1941 / Ed. F. Betti. Milano: Electa, 2011. P. 11-14. 
Urbanistica.comune.roma.it. URL: http://www.urbanistica.comune.roma.it/citta-storica-mausoleoaugusto. html. Дата обращения 25.05.2020.

Vögtle S. »ubi saepe sedebat Octavianus« Das Augustusmausoleum - Innen und Aussen eines imperialen Grabbaus // Das Marsfeld in Rom : Beiträge der Berner Tagung vom 23./24. November 2007 / Ed. J. Albers. Bern: Bern Studies in the History and Philosophy of Science, 2008. P. 63-78.

\section{Информация об авторе}

Маркелов Андрей Юрьевич, кандидат исторических наук, ассистент, Московский городской педагогический университет (Самарский филиал); преподаватель кафедры истории Отечества, медицины и социальны наук, Самарский государственный медицинский университет (г. Самара, Россия); andreymarkelov91@gmail.com

\section{REFERENCES}

Agnoli N., Carnabuci E., Caruso G., Maria Loreti E. 2014. In Abbondanza L., Coarelli F., Lo Sardo E. (eds.). Apoteosi. Da uomini a dei. Il Mausoleo di Adriano, Catalogo della Mostra. Roma: Munus, Palombi, 2014. P. 214-229 (in Italin)

Albers J. 2014. In Antike Welt. 4, 16-24.

Betti F. 2011. In Il Betti, F. (ed.). Mausoleo di Augusto. Demolizioni e scavi. Fotografie 1928/1941. Milano: Electa, 20-41.

Borg, B. 2019. Roman Tombs and the Art of Commemoration: Contextual Approaches to Funerary Customs in the Second Century CE. Cambridge: Cambridge University Press.

Boschung, D. 1980. In Hefte des Archäologischen Seminars der Universität Bern. 1980. No 6, 38-41.

Buchner, E. In Antike Welt. 27(3), 161-168 (in Gerrnan).

Carnabucci E., Agnoli N., Maria Loreti E. 2012. Mausoleo di Augusto. Available at: :http://www.fastionline. org/excavation/micro_view.php?fst_cd=AIAC_2307\&curcol=sea_cd-AIAC_4480. (accessed 30.05.2020)

Coletti C. M., Naria Loreti E. 2016. In MAAR. No 61, 304-325.

Collini, M. A., Ciglioli, G. Q. 1926. In BCom.No 54, 191-237.

Davies, P. J. E. 2000. Death and the Emperor: Roman Funerary Monuments from Augustus to Marcus Aurelius. Cambridge, New York: Cambridge University Press.

Diebner, S. 2013. In J. DeRose Evans (ed.). A Companion to the Archaeology of the Roman Republic. Malden: Wiley-Blackwell, 67-80.

Fugate Brangers, S. L. 2013. In International Journal of Humanities and Social Science. No 3, 126-135.

Fugate Brangers, S. L. 2007. The mausoleum of Augustus: expanding meaning from its inception to present day. PhD Diss. Louissville.

Gatti, G. 1938. In L'Urbe. No 3, 1-17.

Giglioli, G. Q., Colini, A. M. 1930. II Mausoleo d'Augusto. Milan and Rome: Bestetti e Tumminelli.

Hase Salto, M. A. 1997. In Antike Welt. 28, 297-308 (in German)

Hesberg, H., Panciera, S. 1994. Das Mausoleum des Augustus. Der Bau und seine Inschriften. München: Bayerische Akademie der Wissenschaften.

Johnson, M. J. 1996. In John F. Hall (ed.). Etruscan Italy. Etruscan Influences on the Civilizations of Italy from Antiquity to the Modern Era. Provo, 217-239.

La Manna S., G. Caruso, Agnoli N., Carnabucci E., Loreti E., 2008. Documento preliminare alla progettazione. Available at: http://sovraintendenzaroma.it/sites/default/files/storage/original/application/368f c32a188973a80557f3f49e3409f3.pdf. (accessed 28.05.2020.)

Lanciani R. 1903. Storia degli scavi di Roma e notize intorno le collezioni Romane di antichità. Vol. II. Roma: Ermanno Loescher\&Co.

Lanciani, R. 1897. The Ruins and Excavations of Ancient Rome. London: Mac Millan.

McFeaters, A. P. 2007. In Nebraska Anthropologist. 33, 49-69.

Mirabilia Romae e codicibus vaticanis emendate. 1896. In G. Parthey (ed.). Berolini: in aedibus Frederici Nicolai.

Nash, E. 1961. Pictorial Dictionary of Ancient Rome. Vol .I. London: A Zimmer Ltd.

Ortolani, G. 2004. In BCom. 2004. Vol. 105, 197-222. 
Parker, J. 1989. In The American Journal of Archaeology. 93, 137-141.

Reeder, J. C. 1992. In Classical Antiquity, 11. 265-307. (in English)

Riccomini, A. M. 1996. La Ruina di si bela cosa. Vicende e transformationi del Mausoleo di Augusto. Milano: Electa (in Italian).

Sovraintendenzaroma.it. Available at: http://www.sovraintendenzaroma.it/i_luoghi/roma_antica/ monumenti/mausoleo_di_augusto. (accessed 01.06.2020)

Tittoni, M. E. 2011. In Betti, F. (ed.). Il Mausoleo di Augusto. Metamorfosi di un monument Mausoleo di Augusto. Demolizioni e scavi. Fotografie 1928/1941 . Milano: Electa, 11-14. (in Italian)

Urbanistica.comune.roma.it. Available at: http://www.urbanistica.comune.roma.it/citta-storicamausoleoaugusto.html. (accessed 25.05.2020. )

Vögtle, S. 2008. »ubi saepe sedebat Octavianus« Das Augustusmausoleum - Innen und Aussen eines imperialen Grabbaus In Albers J. (ed.) Das Marsfeld in Rom : Beiträge der Berner Tagung vom 23-24.11.2007. Proceedings Bern: Bern Studies in the History and Philosophy of Science, 63-78.

\section{About the Author:}

Markelov Andrei Yu. Candidate of Historical Sciences, Asistent, Moscow City Pedagogical University (Samara brash), Stara Zagora Str., 76, Samara, 443081, Russian Federation; Samara State Medical University, Chapaevskaya Str., 89, Samara, 443099, Russian Federation; andreymarkelov91@gmail.com

Статья поступила в журнал 01.08.2020 г. Статья принята к публикации 01.09.2020 г. 